Erratum: Integrating genotypic and expression data in a segregating mouse population to identify 5-lipoxygenase as a susceptibility gene for obesity and bone traits

M Mehrabian, H Allayee, J Stockton, P Y Lum, T A Drake, L W Castellani, M Suh, C Armour, S Edwards, J Lamb, A J Lusis \& E E Schadt Nat. Genet. 37, 1224-1233 (2005).

The first sentence of the first paragraph in the Results section should begin, "In the BXD cross, female $\mathrm{F}_{2}$ mice homozygous with respect to the DBA/2J (DBA) allele at the Alox5 locus had higher fat mass...". The fourth sentence in the legend to Figure 2 should begin, "Regions with five or more SNPs in a 25-kb interval were designated non-IBD between B6 and DBA...”.

\title{
Corrigendum: Disruption of Bardet-Biedl syndrome ciliary proteins perturbs planar cell polarity in vertebrates
}

A J Ross, H May-Simera, E R Eichers, M Kai, J Hill, D J Jagger, C C Leitch, J P Chapple, P M Munro, S Fisher, P L Tan, H M Phillips, M R Leroux, D J Henderson, J N Murdoch, A J Copp, M-M Eliot, J R Lupski, D T Kemp, H Dollfus, M Tada, N Katsanis, A Forge \& P L Beales Nat. Genet. 37, 1135-1140 (2005).

In Figure 1a, the section on the left labeled "2-week-old wild-type" was from an $\mathrm{Mkks}^{-/-}$mouse. The corrected panel appears below.

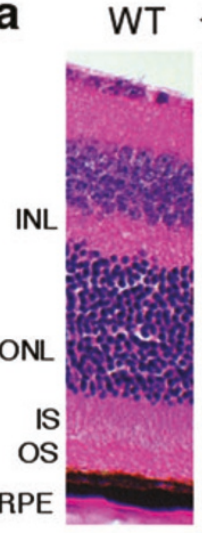

2 week

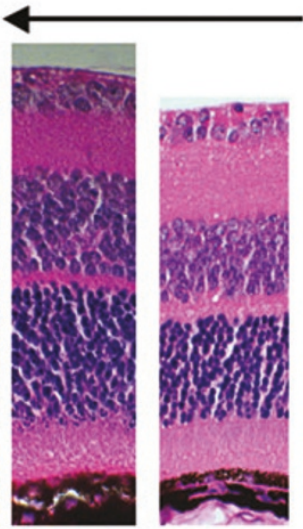

2 week

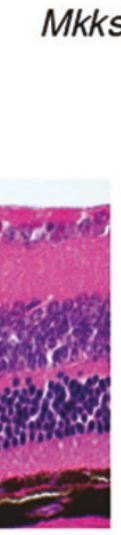

6 week

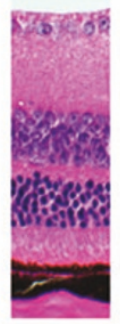

8 week

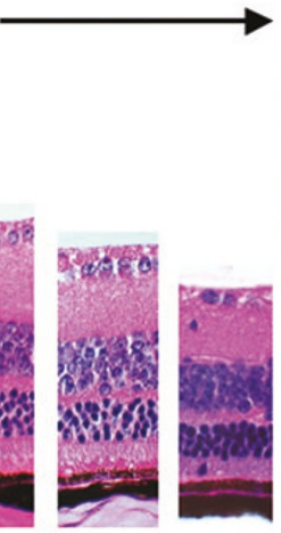

WT

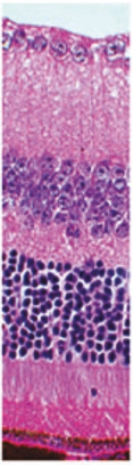

26 week 